\title{
The role of small towns in sustainable rural development
}

\author{
F. Vaccher \\ Department of Architecture and Arts, IUAV University Venice, Italy
}

\begin{abstract}
Although the African continent is still the least densely populated, it is also an area where demographic pressure is growing continuously; in general, however, development patterns have been unsustainable and helped multiply negative factors.

In this context, the sustainable development of the urban areas that are somewhere between the city and country in size becomes an important theme: on the one hand, it is an opportunity to invert the trend towards the polarisation of the large urban centres and the ensuing unchecked urbanisation; on the other, it is a means of keeping under control spontaneous or rather unplanned urbanisation in rural areas that might lead to problems in managing the territory. A small rural centre north of Benin, Matéri was chosen to start an experimental project with the aim of developing a new, rural development model as an alternative to westernstyle planning, able to create a self-sufficient economy in which housing and infrastructures are interwoven with natural resource management, the role of family agriculture, and the reciprocal relations between city and brousse. This research was carried out in the environmental sustainability Atelier of IUAV University Venice, together with the local community and institutions, to provide a solution to indications in the city's document plan.

Keywords: new rural-urban model, sustainable spatial planning, identity of the contemporary African town.
\end{abstract}

\section{Introduction}

Demographic growth, rural exodus and the phenomena of unchecked urbanisation that are often a consequence not only give rise to inevitable social contradictions linked to the irreversible changes of customs and life styles in African society, but also to serious problems regarding territorial management. 
From this perspective, the complexity of the relationship between the countryside and city needs to pay particular attention of the function that the small urban centres could have as an 'intermediary attraction' for the population and sustainable development. This means proposing a lifestyle that has closer ties with the community, respects family and social traditions and customs established, in contrast to the disastrous growth model of the large metropolis with suburbs in which there is a concentration of poverty, under-development and environmental decay.

The clearest expression of poverty at an urban level are slums, precarious, unhealthy settlements that characterise the landscapes of all African cities, assuming such dimensions that one is led to believe they are an actual consequence of urbanisation, the only way in which a city can be built, the forma urbis of Africa in the twenty-first century.

However, there is another path that could be followed, one that challenges the very idea of western planning and that can be applied not only to the urban suburbs that are part of the cities, but also to small cities and rural centres; it is one that proposes new planning models that take into account the culture of the site, protecting the testimony of cultural identity and thus also offering an opportunity for territorial intervention and the re-invention of tradition.

Architecture should give voice to a different way of living, achieved with very few means, controlling the resources that, on the one hand guarantee the preservation of a unique environmental heritage and, on the other, the employment of natural resources, generating a variety of solutions that combine the rich original culture, which is still closely connected to nature, symbols, and myths, with the technological opportunities of nowadays, without renouncing the richness and complexity of new materials and technologies that can be adapted to a climatic, geographical and cultural situation that is totally different from that in the west. However in this transition many things happen, new shapes are added to the existing ones, redrawing the geography of the African territory.

\section{The Matéri project}

The Matéri project becomes significant as it could become an opportunity for territorial invention and re-invention of tradition, as well as an original place to verify how urban projects can become the motors of territorial sustainable transformation and generators of new centrality and quality of living.

Matéri, a small rural centre in the north of Benin was chosen as a test to start a planning experiment carried out by the Atelier of environmental sustainability at IUAV University in Venice, with the aim of developing an urban/rural reference model for the construction of the identity of a contemporary African city that can also be applied to other parts of the territory around Benin.

Situated in the department of Atakora, $600 \mathrm{~km}$ to the north of the capital Cotonou, it covers around $1,740 \mathrm{~km}^{2}$ and is divided into 6 arrondissements with a total of 55 villages.

This area is characterized by agricultural functions and activities based on a rural type of social, economic and cultural background. 
From the satellite picture of Materi the following elements are recognizable: the urban agglomerate where the institutional buildings and the market are located; the agricultural areas (savane à emprise agricole) spreading in the small villages into the central part of the territory; the wild-pastoral areas concentrated in the west; the naturalistic emergences of the Park of Pendjari in the north. The territory, covered by a savannah of shrubbery and trees, is crossed by many water courses, most of which are seasonal.

In this context, the population is totally dependent on natural resources as there is no kind of industrial activity to transform agricultural products.

The persistence of settlement patterns, the typology of housing and local construction techniques should be underlined. In fact, the landscape is still dominated by housing compounds in which large polygamous families arrange their huts made of unbaked earth and straw circularly around a large patio that is dominated by a tall fruit tree, which is where all domestic chores and sustenance take place. However, the traditional living culture is developing towards a 'conventional' housing model that consists in a compact building, built in concrete blocks with a sheet-metal roof; this is a characteristic of the suburbs of the main cities, and is a model that reflects the aspirations for an urban life style.

However, this housing typology has several disadvantages: the spatial organisation is not suited to the local culture; it is too expensive for most of the population; it has been shown to perform poorly as regards comfort; it is also resulting in a loss of cultural heritage and local knowledge.

Today the municipality has around 100,000 inhabitants but a significant development of the population is foreseen over the next 15 years, with a forecast of 200,000 inhabitants in 2030 .

The need to manage this expected urban growth led the administration to promote the drafting of a city plan $[1,2]$ that mainly foresees:

- development and concentration of new settlements - in a strip of expansion around the present nucleus of houses - following a controlled plan of soil occupancy and providing them with the basic services;

- strengthening the urban settlement along the main itinerary with the addition of: aggregation places (urban youth centre, centres devoted to sport and young people associations) and new facilities (schools, sport places, agricultural warehouses, markets, laboratories for the production/ transformation of agricultural products, laboratories and centres for professional education and start-ups);

- concentrating the administrative buildings in the area located in the north of the existing residential nucleus;

- developing a commercial area in the south part of the settlement in order to grant continuity with the existing market;

- contributing to an improvement in the life style in the existing districts with their inclusion in a holistic project of sustainable development of the territory;

- development of new touristic structures respecting the presence of the natural Park of Pendjari - a UNESCO heritage site - and following the criteria of sustainable management in order to control the development of this precious part of the territory and of its natural resources. 


\section{Urban architecture for rural sustainable development}

Starting with the general guidelines included in the development plan of Matéri in the form of a case study - the Atelier experimented new settlement models, fig. 1 , able to assimilate the culture of the place in their configuration and to recover and consolidate the local know-how, enriched by technological innovations and the exploitation of the natural renewable resources.

This required the adoption of processes that were suitable to the context and could be repeated by local communities.
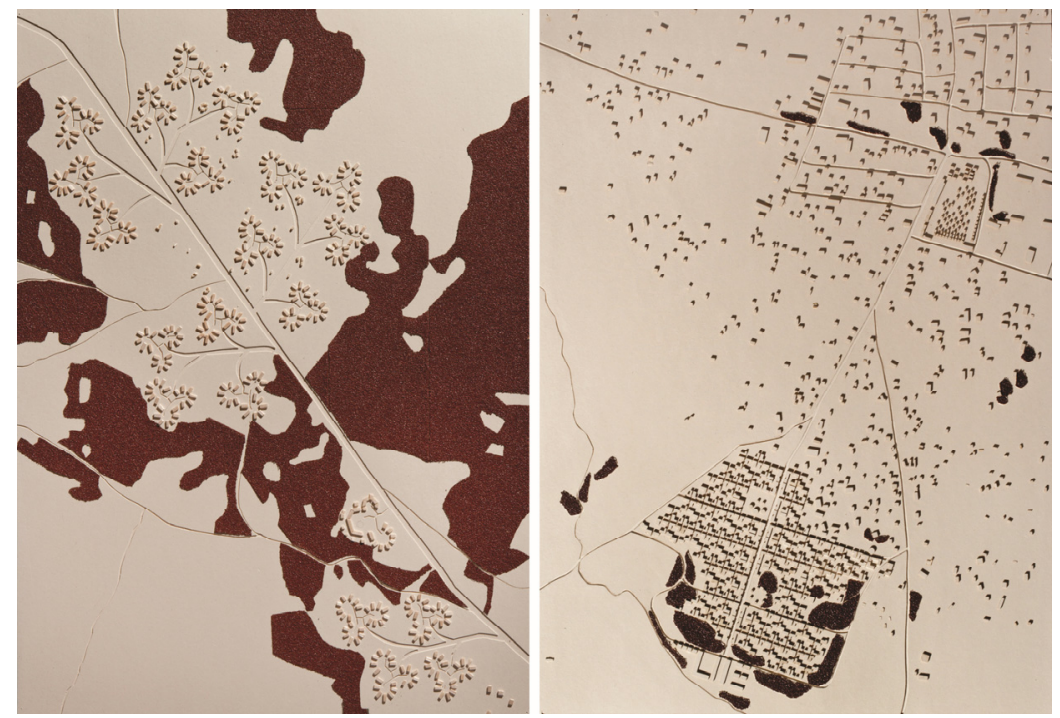

Figure 1: Experimental urban/rural settlements: a selection of the planning projects developed by the students. The images submitted do not exhaust the illustration of the individual proposals but show the planning strategies adopted.

The main objective of this approach was to contribute to the translation of the contents of the Matéri Development Plan whilst also giving an image of the places that were the object of this transformation in order to start a debate with the local community on the issue.

This resulted in a trip/internship period in May 2014 when activities were organised to involve the community and local technicians with the two-fold objective of primarily discussing the projects selected and assessing, with the involvement of the population, any possible repercussions in both terms of feasibility and acceptance.

The opportunity of this "participated atelier" opens new scenarios for the education of the local technicians who, in their professional role, will have to face the problems connected with the realization and reproducibility of the projects, personalizing them each time according to their own particular context. 
African rebirth does not mean copying the urban forms of pre-colonial cities or their architecture; it is clear that the problems of contemporary society are different and that life styles have changed; however, an understanding of these forms and their characteristics is necessary, as it offers material that can be reworked, reinterpreted, and adapted to the needs of those who are involved in its creation today.

Dealing with these territories means evoking the tools of different disciplines, from geography to anthropology, from architecture to climatology, assuming a complexity that overcomes the simple architectural artefact, determining multiple connections both at a local and global level.

With the aid of the exploration of research topics with strong spatial implications, the interest in research for new models of urban development in a rural context has been the verification of ways in which such intervention could become the engines of a sustainable transformation of the territory, generators of new centralities and of the quality of living.

Seen as urban explorations for the development of Matéri, the resulting projects provide an answer to the general topics hitherto evoked, proposing expansion strategies through the construction of autonomous residential districts from the existing central nucleus. These districts will increase in dimension and identity in the near future, whilst always taking into account the context, without setting aside the collective memory and the immaterial dimension of the local myths and sacred spirit which are still integral elements of the African architecture [3].

The starting point for the construction of new quarters is the "minimal unit" of the room/lodging and it is around this that the living units are developed, following a freedom of aggregation that is a component of the form of the new housing agglomerates, to create the idea of 'modulated densification' that can be applied to the African rural context that is characterized its territorial dispersion.

However, the consolidated concepts of western tradition must be overcome. In fact, in the African culture the house is never seen as a static concept; on the contrary, it is a dynamic process of mono-functional rooms, which reflect the development and transformation of the people living there.

Bearing in mind that most of the people that will live in the expansions come from the surrounding rural areas, particular attention was paid to maintaining some characteristics of the typical African house in the aggregation spaces, such as the courtyard - an essential component for the environmental control and for the sociocultural exchanges, fig. 2 .

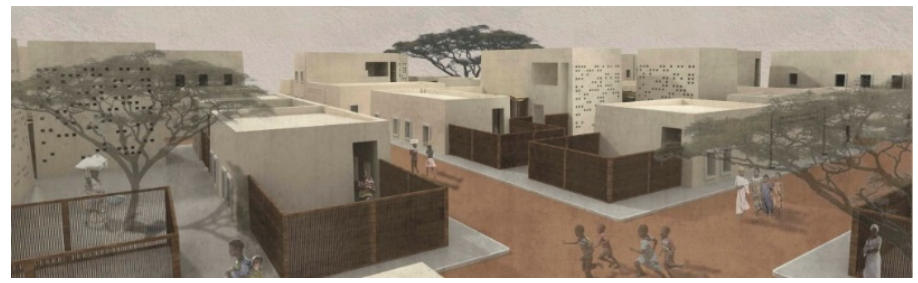

Figure 2: House type: view of the courtyards (project by C. Gianni, S. Righetto and D. Volpato). 
In general, the transformation strategies adopted in residential settlements not only experiment the various hypothesis of modulated density and settlement typologies that are flexible with time, but also introduce forms of agriculture and vegetable gardens (to help encourage the self-sufficiency of the settlements) as well as market areas and equipment for public use, with new central structures and local services.

Although in areas of diverse expansion, all the projects act on morphologically similar fabric and can therefore be taken as a 'model' for other areas with similar contextual conditions.

In the strategies of urban expansion adopted, the public facilities and the collective buildings assume a very important role, each time giving a well-defined character to the residential area: they are in fact the generating elements that create new recognizable places [4].

It is possible to speak of a "settlement character" of the new facilities which result in a design and hierarchy of the open spaces, introducing new centralities such as the market areas connected to the production, processing and sale of the agricultural products with the relative classrooms and laboratories for professional training (agricultural centres), the urban centre, schools, accommodation facilities in order to stimulate the development of tourism thanks to the presence of the Pendjari Park.

The typology of the buildings is often the result of the hybridization of living places and collective spaces, since there is not much difference between domestic architecture and larger complexes dedicated to sacred or civil uses in African culture [5].

If the housing unit is the module of the settlement system, owing to its dimensions it is the field that regulates the planning of the land on a territorial scale; if the courtyard in the urban nucleus is the fulcrum for family life, in the public space of the agricultural centre it becomes the meeting place with study spaces (training laboratories, classroom), and work spaces (greenhouses, craftsmen workshops, small craftsmen workshops for the transformation of products such as milk, sales points).

The space dedicated to the production, the processing and the storage of raw materials will be placed in an area near the field directly in contact with the market for the selling of agricultural products.

New farming practices require new, innovative spatial and functional solutions, so all the projects have the objective of creating an agricultural plan that corresponds to African resources and requirements.

The proposed solutions for the urban centre, fig. 3 , seen as a place for meetings and education, provide a complex of buildings housing rooms for teaching, a library open to the city, educational workshops linked to the presence of vegetable gardens, places for the sale of products, and a canteen. The most important aspect is the relationship between the various parts of the buildings, since the shape of the complex, as suggested by the study of the traditional houses of Tatasomba, is secondary [6]. 


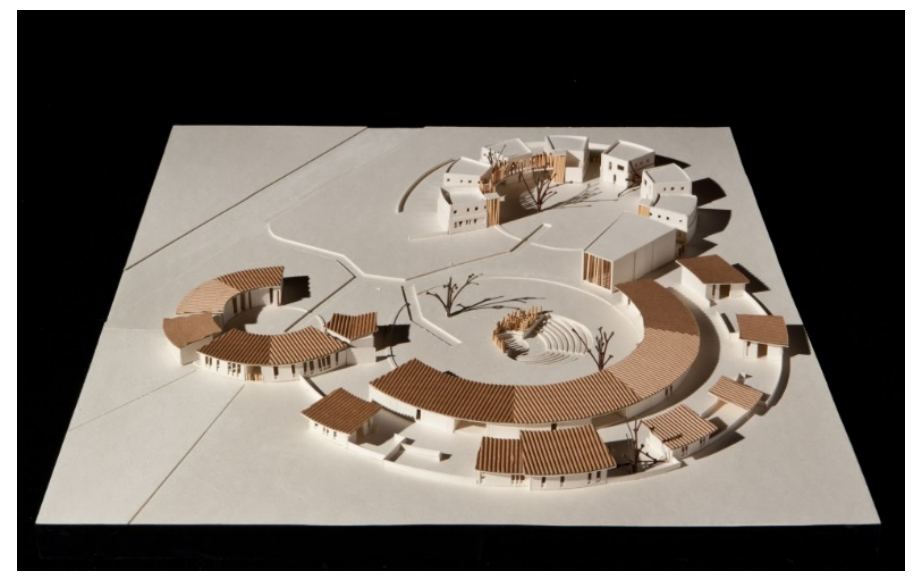

Figure 3: Urban centre: ground floor plan: accommodation for visitors, rooms for teaching, canteen, library and office (project by G. Bolzanella and M. Polato).

The common element underlying the accommodation projects is the attention paid to the ecosystem, to the different topics of the landscape and the territory and their interrelationship from small to large scale.

The projects take shape beginning with the elementary layout on which the buildings that house the reception places are based (hall, reception, restaurant, shops) and some of the rooms, in contrast to the casual distribution of the 'bungalows' built using traditional techniques that recall the typical African house, figs 4 and 5 .

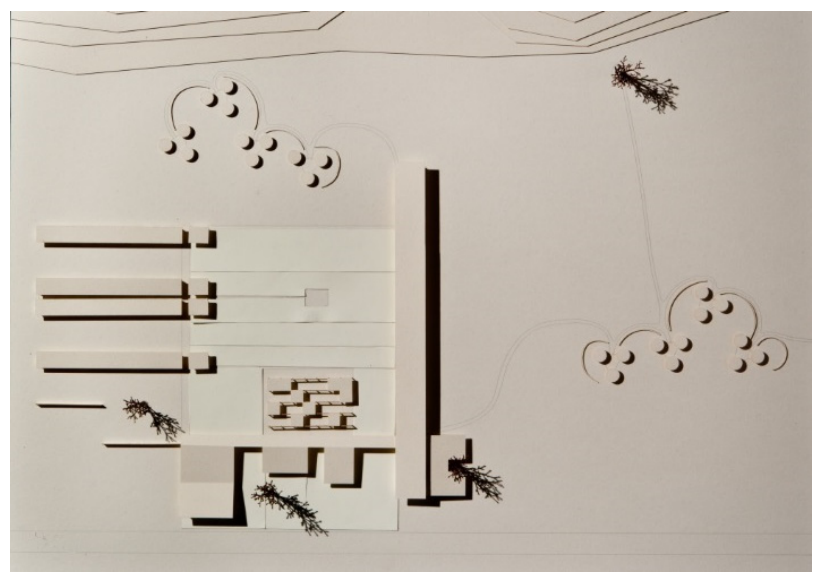

Figure 4: Accommodation facilities: general site plan. The main building with reception area, shops, a café open to the public, the residences and the private bungalows (project by M. Becevello, A. Calandriello and F. Zanibellato). 


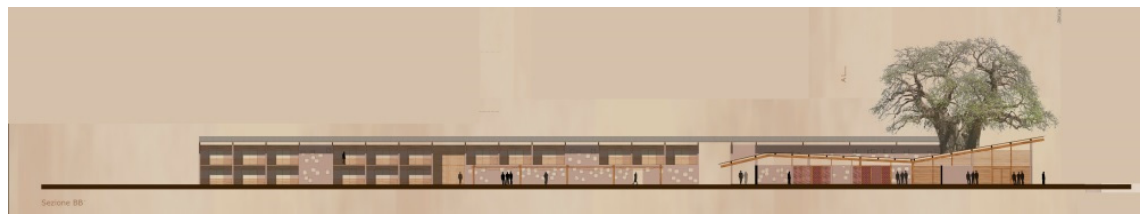

Figure 5: Accommodation facilities: front view. The main building with hall and residences (project by M. Becevello, A. Calandriello and F. Zanibellato).

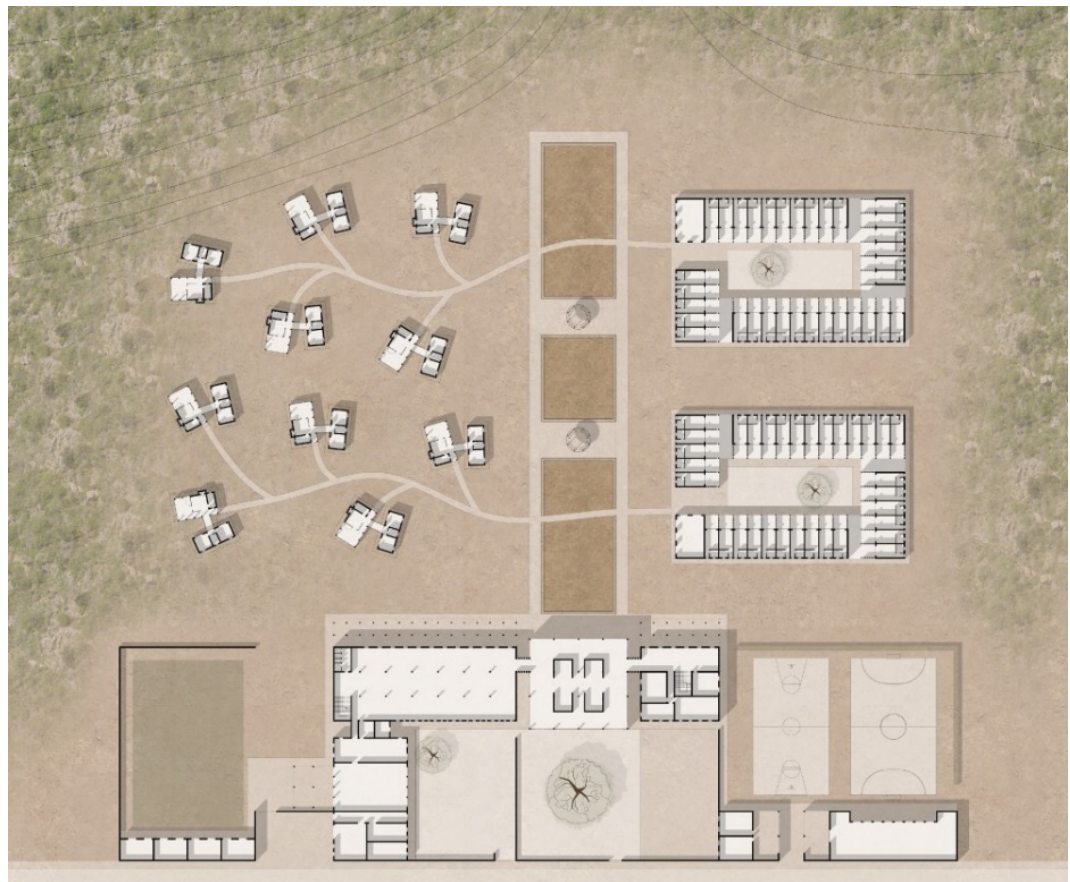

Figure 6: Accommodation facilities: general site plan. (Project by P. Guidolin, F. Parolin and C. Sottana).

A functional and aesthetic architectural 'system' that consists in a network of paths organises the layout, integrating the accessory and service buildings as well.

The main strategy behind all these projects is the stimulation of an ecosustainable agriculture and preservation of the rural characteristics - still very frequent in Matéri - integrating them with the emerging urban characters.

The purpose of the integration of different forms of social-economics and spatial organization has two goals: on the one hand, to support the modernization of the urban structure, and on the other hand, through the creation of local microchains and the education of the new generations, to trigger a mechanism able to generate profit and guarantee the subsistence of the population. 


\section{Conclusion}

The formulation of the city plan made the Administration's objective clear from the very beginning: modernizing Matèri where possible whilst concentrating in particular on the expansion and infrastructural equipment of the existing nuclei and the addition of new collective activities, thus trying to overcome inequality and the fight against poverty.

The proposals developed by the Atelier wanted to offer real answers to these needs, suggesting not only planning strategies but also concrete answers in sustainable projects, based on strategies that are suited to the context as regards the use of materials and renewable energy sources, the feasibility of which was also recognized by the town council Administration itself during meetings in loco.

Taking Matèri as a pilot project, the objective of this experience was also the definition of a development model that could be adopted by other local administrations of Benin in their planning of sustainable growth in rural cities as well.

\section{References}

[1] Republique du Bénin, Department du l'Atacora, Commune de Matéri, Plan de developpement de la Commune de Matéri. PDC Matéri, 2010.

[2] Republique du Bénin, Department du l'Atacora, Commune de Matéri, Schema directeur d'amenagement de la Commune de Matéri. SDAC Commune de Matéri, 2010.

[3] Piot, C., Remotely Global: Village Modernities in West Africa, (Chapter 6). Community: Spirits, Mimesis, Modernity, The University of Chicago Press, pp. 131-155, 1999.

[4] Fassassi, M. A., L'architecture en Afrique noire. Cosmoarchitecture, L'Harmattan, pp. 14, 173-176, 1978.

[5] Arecchi, A., Abitare in Africa: architetture, villaggi e città nell'Africa subsahariana dal passato al presente, Mimesis Liutprand, p. 26, 1998.

[6] Preston Blier, S., The anatomy of architecture. Ontology and metaphor in Batammaliba architectural expression, The University of Chicago Press, Chicago and London, pp. 12-18, 1987. 